\title{
IN ERINNERUNG AN PROFESSOR GEOFFREY BURNSTOCK (1929-2020)
}

\section{Liebe Kolleginnen und Kollegen,}

Professor Geoffrey Burnstock war einer derjenigen Forscher, die ganz wesentlich zurWeitererforschung der Akupunktur beigetragen haben. Er unterstützte zahlreiche wissenschaftliche Gesellschaften als Ehrenmitglied und war darüber hinaus der am häufigsten zitierte Wissenschaftler in Pharmakologie und Toxikologie in den Jahren 1994 2006. Seine Arbeiten wurden über $60.000 \mathrm{Mal}$ zitiert und er konnte auf einen Hirsch (h) -Index von 112 hinweisen.

Professor Burnstock, AC FAA FRS FMedSci war Neurobiologe in London und Präsident des Autonomic Neuroscience Center der UCL Medical School. Er ist am besten dafür bekannt, den Begriff „Purinerge Signalübertragung" geprägt zu haben, welche er in den 1970er-Jahren entdeckte. Er ging im Oktober 2017 im Alter von 88 Jahren in den Ruhestand.

Der ebenfalls bereits verstorbene Nobelpreisträger Professor Sir James Black, der Geoffrey Burnstock als Kandidat für den Nobelpreis nominierte, beschrieb den Forscher in einem Wort - ,evervescent “ -, was normalerweise mit sprudelnd, überschäumend und quirlig übersetzt wird. Neben zahlreichen internationalen Auszeichnungen erhielt Burnstock im Jahr 2017 eine Ernennung zum Honorarprofessor an der Chengdu Universität für Traditionelle Chinesische Medizin (TCM) in Anerkennung seiner bedeutenden Leistungen in der TCM. Die Ehre war in Anerkennung seiner Hypothese über einen möglichen zugrunde liegenden Mechanismus der Akupunktur, der international erhebliche Aufmerksamkeit erregt hat. Seine Hypothese wurde in zahlreichen wissenschaftlichen Artikeln beschrieben. Über seine Zusammenarbeit mit Chinesischen Wissenschaftlern wurde ebenfalls ausführlich berichtet.

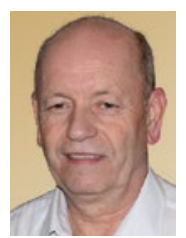

Dr. med. Dipl. Chem. Michael Weber

President for Medical and Clinical Applications der International Society for Medical Laser Applications

(ISLAtranscontinental)

Sohnreystrasse 4

37697 Lauenförde

Internet: www.isla-laser.org

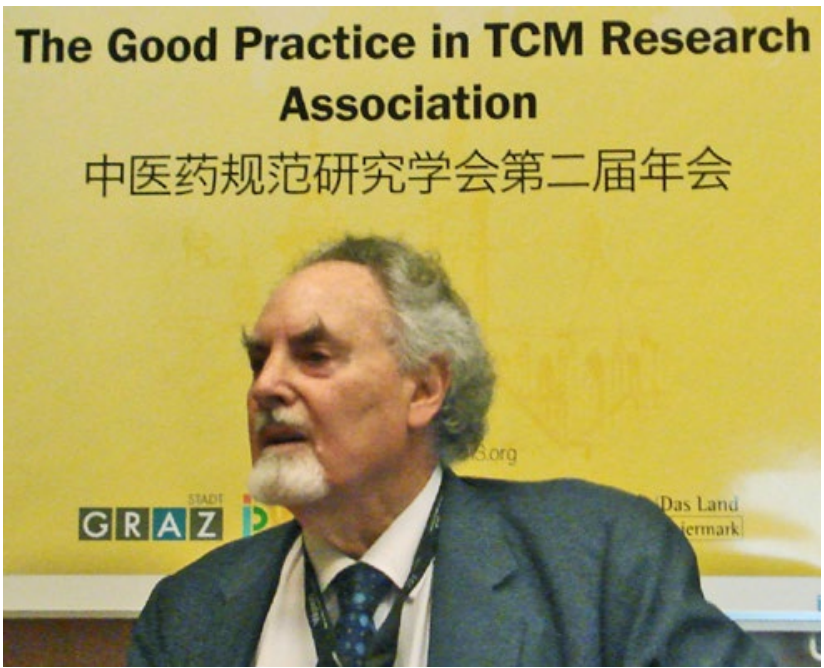

Abb. 1: Prof. Geoffrey Burnstock (1929-2020) bei seinem Vortrag im Jahre 2013 am TCM-Forschungszentrum in Graz (Foto (C) G. Litscher)

Prof. Geoffrey Burnstock war auch Vortragender am TCM Forschungszentrum in Graz. Am 30. August im Jahre 2013 (Abb. 1) begeisterte Burnstock zahlreiche internationale ForscherInnen, die zu einer wissenschaftlichen Tagung nach Graz gekommen waren, mit einem Vortrag „Purinergic signalling and the hypothesis for its involvement in acupuncture“. Burnstock verstab am 2. Juni 2020 im Alter von 91 Jahren.

Allen Leserinnen und Lesern dieser Ausgabe wünschen wir weiterhin ein hoffentlich gesundes Jahr 2020.

G. Litscher

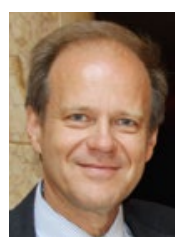

Univ.-Prof. Prof. h.c. DI Dr. techn.

Dr. scient. med.Gerhard Litscher

President for Science and Research der International Society for Medical Laser Applications (ISLAtranscontinental)

Medizinische Universität Graz, Auenbruggerplatz 39, EG19, A-8036 Graz, Tel: +43 316/385-83907 E-Mail:gerhard.litscher@medunigraz.at 